\title{
Oligomeric Electrolyte as a Multi-Functional Gelator
}

\author{
Masaru Yoshida, ${ }^{*}{ }^{\dagger}$ Nagatoshi Koumura, ${ }^{\dagger}$ Yoshihiro Misawa, ${ }^{\dagger}$ Nobuyuki \\ Tamaoki, ${ }^{\dagger}$ Hajime Matsumoto, ${ }^{\S}$ Hajime Kawanami, ${ }^{\complement}$ Said Kazaoui, ${ }^{\perp}$ \\ Nobutsugu Minami ${ }^{\dagger}$ \\ ${ }^{\dagger}$ Nanotechnology Research Institute, National Institute of Advanced Industrial Science and \\ Technology (AIST), 1-1-1 Higashi, Tsukuba, Ibaraki 305-8565, Japan \\ ${ }^{\ddagger}$ Photonics Research Institute, AIST, 1-1-1 Higashi, Tsukuba, Ibaraki 305-8565, Japan \\ ${ }^{\S}$ Research Institute for Ubiquitous Energy Devices, AIST, 1-8-31, Midorigaoka, Ikeda, \\ Osaka 563-8577, Japan \\ ${ }^{9}$ Research Center For Compact Chemical Process, AIST, 4-2-1, Nigatake, Miyaginoku, \\ Sendai, Miyagi 983-8551, Japan \\ ${ }^{\perp}$ Research Center for Advanced Carbon Materials, AIST, 1-1-1 Higashi, Tsukuba, Ibaraki \\ 305-8565, Japan
}

\section{Supporting Information}

General Procedure. ${ }^{1} \mathrm{H}$ NMR spectra were recorded on a Varian VXR-300 (300 MHz). Chemical shifts are denoted in $\delta$-unit (ppm) relative to $\mathrm{D}_{2} \mathrm{O}$, or DMSO- $d_{6}$. The solvents were distilled and dried, if necessary, by standard methods. Triethylamine was dried over potassium hydroxide and distilled before use. The other reagents and starting materials were used as obtained from Aldrich, Wako, Kanto Chemical, TCI and Merck. Single walled carbon nanotube (SWNT) (HiPco, CNI, as produced) was purchased from Sumitomo Corporation and used without further purification. UV-vis-NIR spectra were recorded on a Shimadzu UV-3150 or UV-3101 spectrometers. FT-IR spectra were recorded on a 
Mattson Infinity Gold FTIR spectrometer using an air-tight cell and $\mathrm{CaF}_{2}$ optical nanocrystals. Field emission scanning electron microscope (FE-SEM) image was obtained using a Topcon DS-720. The xerogel for FE-SEM was converted from the hydrogel of $\mathbf{1 \cdot C l}$ by freeze drying in vacuo using the EYELA FDU-1200 instrument.

\section{Synthetic Procedures:}

Ionic Oligomer 1·Cl: To a suspension of 4-aminopyridine $(12.2 \mathrm{~g}, 130 \mathrm{mmol})$ in dichloromethane (200 $\mathrm{mL})$ and triethylamine $(143 \mathrm{mmol}, 20 \mathrm{~mL})$ was added dropwise a solution of 4-chloromethylbenzoylchloride $(130 \mathrm{mmol}, 23.9 \mathrm{~g})$ in dichloromethane $(100 \mathrm{~mL})$. The reaction mixture was refluxed overnight. After cooling, precipitates were filtered off, washed with dichloromethane and methanol, and dried under vacuo to afford white powder $(25.5 \mathrm{~g}, 80 \%) ;{ }^{1} \mathrm{H}$ NMR $\left(300 \mathrm{MHz}, \mathrm{D}_{2} \mathrm{O}\right) \delta$ $8.77(2 \mathrm{H}), 8.31(2 \mathrm{H}), 8.05(2 \mathrm{H}), 7.66(2 \mathrm{H}), 5.83\left(\mathrm{CH}_{2}, 2 \mathrm{H}\right)$; IR $\left(\mathrm{D}_{2} \mathrm{O}, \mathrm{cm}^{-1}\right)$ 3390, 1691, 1634, 1516, 1490, 1460, 1423, 1393, 1355, 1321, 1302, 1278.; Elemental Analysis. Calcd for $\left(\mathrm{C}_{13} \mathrm{H}_{11} \mathrm{ClN}_{2} \mathrm{O}\right)_{\mathrm{n}}$ : $\mathrm{C}$, 63.29; H, 4.49; N, 11.36; Obsd C, 61.32; H, 4.71; N, 10.80.

1·TFSI: To a solution of the ionic oligomer $\mathbf{1} \cdot \mathbf{C l}(190 \mathrm{mg})$ in hot water $(25 \mathrm{~mL})$ was added a solution of lithium bis(trifluoromethanesulfonyl)imide (LiTFSI, $1.11 \mathrm{~g})$ in water $(10 \mathrm{~mL})$. The reaction mixture was refluxed for $30 \mathrm{~min}$. After cooling, precipitates were filtered off, washed with water, and dried under vacuo to obtain the ionic oligomer 1·TFSI $(300 \mathrm{mg}, 79 \%)$ as white solids; ${ }^{1} \mathrm{H}$ NMR $(300 \mathrm{MHz}$, DMSO-d $)_{6} \delta 11.66(\mathrm{NH}, 1 \mathrm{H}), 8.96(2 \mathrm{H}), 8.34(2 \mathrm{H}), 8.07(2 \mathrm{H}), 7.67(2 \mathrm{H}), 5.84\left(\mathrm{CH}_{2}, 2 \mathrm{H}\right)$; IR (acetonitrile, $\mathrm{cm}^{-1}$ ).; 3628, 3545, 3319, 3287, 1709, 1643, 1596, 1522, 1329, 1256, 1227, 1198. 
1.PF $\mathbf{6}$ : To a solution of the ionic oligomer $\mathbf{1} \cdot \mathbf{C l}(860 \mathrm{mg})$ in hot water $(200 \mathrm{~mL})$ was added a solution of ammonium hexafluorophosphate $\left(\mathrm{NH}_{4} \mathrm{PF}_{6}, 625 \mathrm{mg}\right)$ in water $(20 \mathrm{~mL})$. The reaction mixture was refluxed for $10 \mathrm{~min}$. The precipitate was filtered off, washed with water, and dried under vacuo to obtain the ionic oligomer $\mathbf{1} \cdot \mathbf{P F}_{\mathbf{6}}$ quantitatively $(1.24 \mathrm{~g})$ as white solids; ${ }^{1} \mathrm{H}$ NMR $\left(300 \mathrm{MHz}, \mathrm{DMSO}-d_{6}\right) \delta 11.65$ $(\mathrm{NH}, 1 \mathrm{H}), 8.94(2 \mathrm{H}), 8.33(2 \mathrm{H}), 8.06(2 \mathrm{H}), 7.66(2 \mathrm{H}), 5.83\left(\mathrm{CH}_{2}, 2 \mathrm{H}\right)$; IR (acetonitrile, $\left.\mathrm{cm}^{-1}\right)$; 3631 , $3541,3320,3288,1709,1643,1596,1522,1327,1256,1207,1170$.
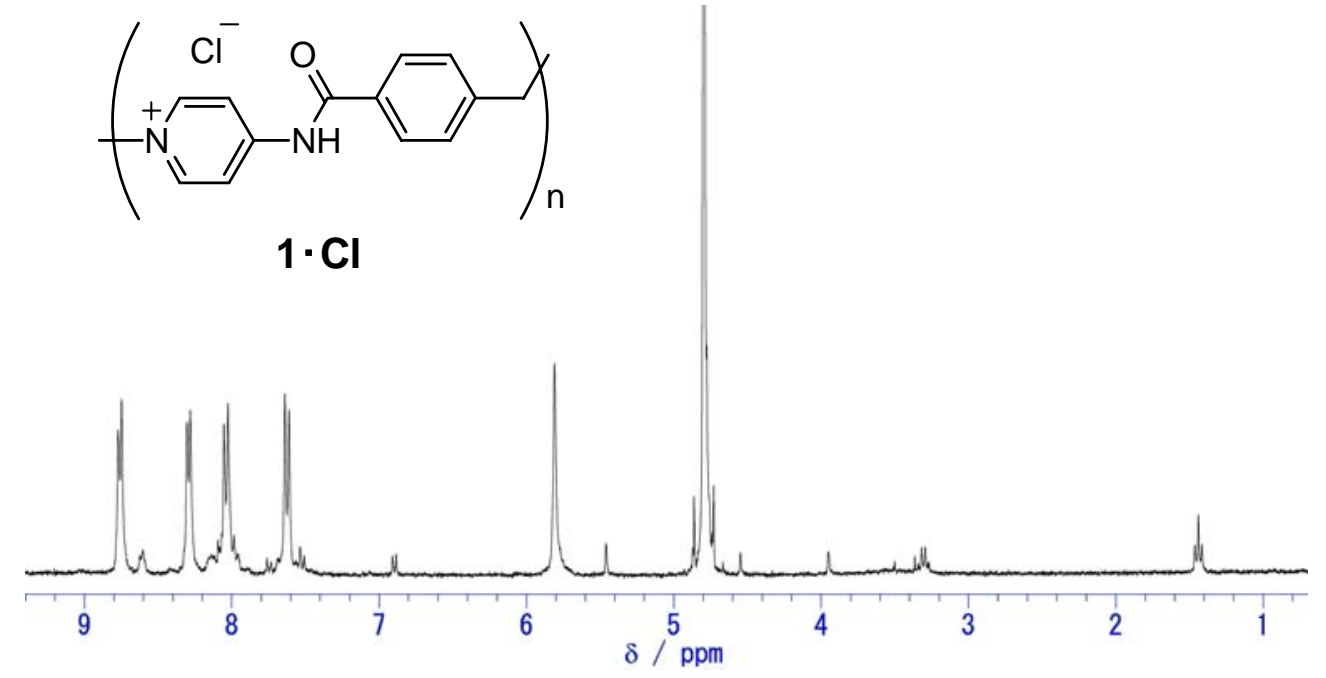

Figure S1. ${ }^{1} \mathrm{H}$ NMR spectrum of $\mathbf{1} \cdot \mathbf{C l}$ in $\mathrm{D}_{2} \mathrm{O}$. 


\section{SEC Analysis:}

Molecular weight of the ionic oligomer 1·TFSI was determined by size exclusion chromatography (SEC), which was conducted on a Shimadzu system comprising an LC-10ADvp pump unit, an SPD-10Avp UV detector $(\lambda=280 \mathrm{~nm})$, a CTO-10Avp column oven, and an SCL-10Avp controller, on the Asahipak column (GF-310 HQ $\left(\right.$ Shodex $\left.^{\circledR}\right)$, PVA gel, upper $M_{w}$ limit: 40,000 Da) in dimethylformamide (DMF) eluent containing $30 \quad \mathrm{mM}$ or $5 \mathrm{mM}$ of lithium bis(trifluoromethanesulfonyl)imide (LiTFSI) at $40{ }^{\circ} \mathrm{C}$. Polystyrene standards were used for the determination of the molecular weight of 1-TFSI using the GPC profile observed at the $30 \mathrm{mM}$ of LiTFSI condition. The SEC profiles were described in Figure S2.

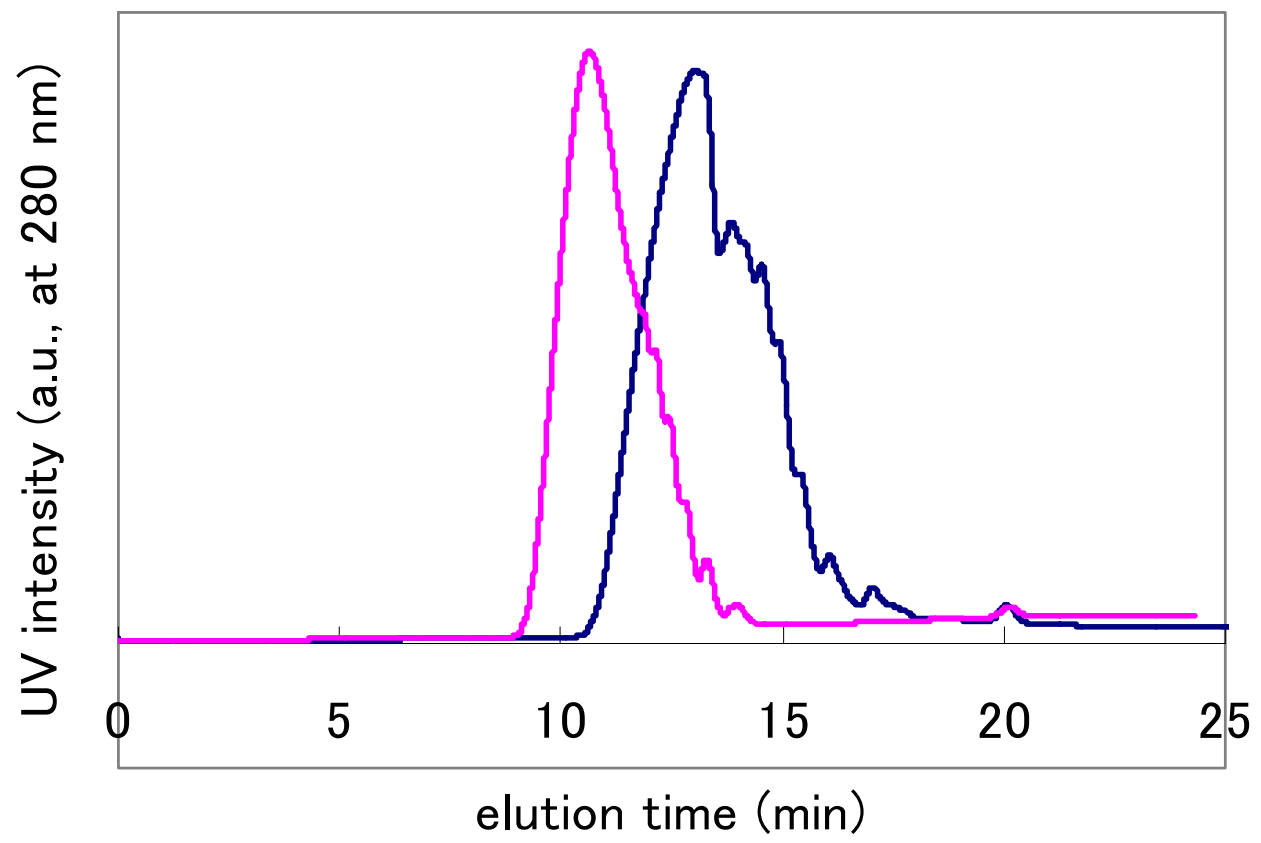

Figure S2. SEC profiles of the ionic oligomer 1·TFSI. DMF eluents containing lithium bis(trifluorometahnesulfonyl)imide (LiTFSI) at $30 \mathrm{mM}$ (pink) or $5 \mathrm{mM}$ (blue) concentrations were used, respectively. 


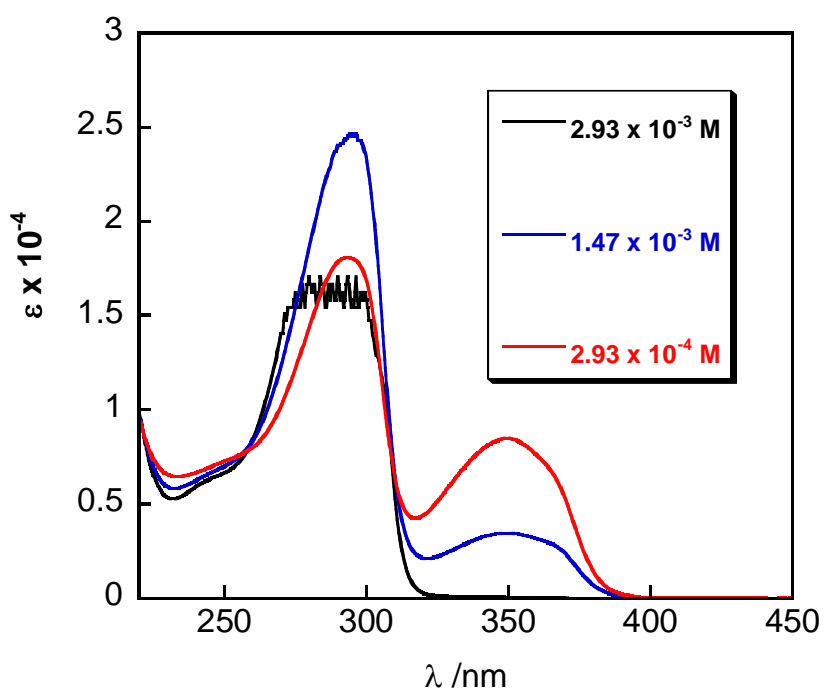

Figure S3. UV spectra of $\mathbf{1} \cdot \mathbf{C l}$ in $\mathrm{H}_{2} \mathrm{O}$ (Optical path length $\left.=1 \mathrm{~mm}\right)$. 
(a)

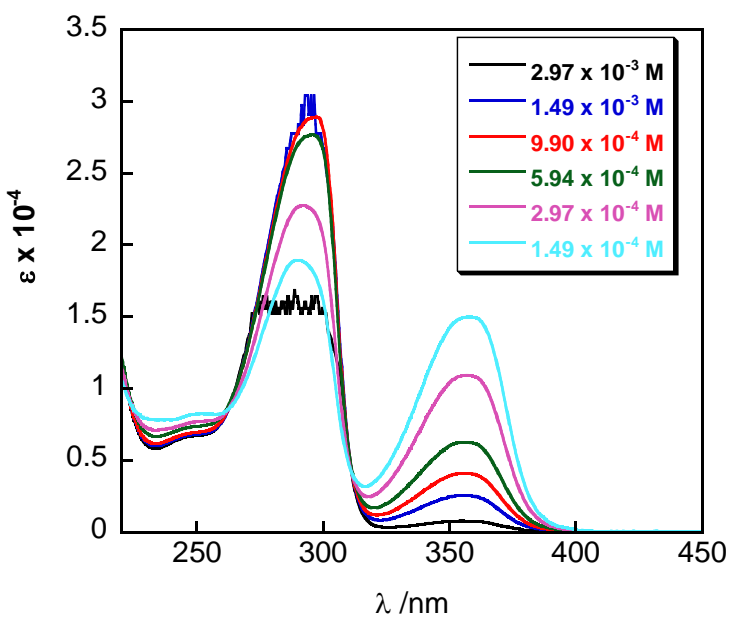

(b)

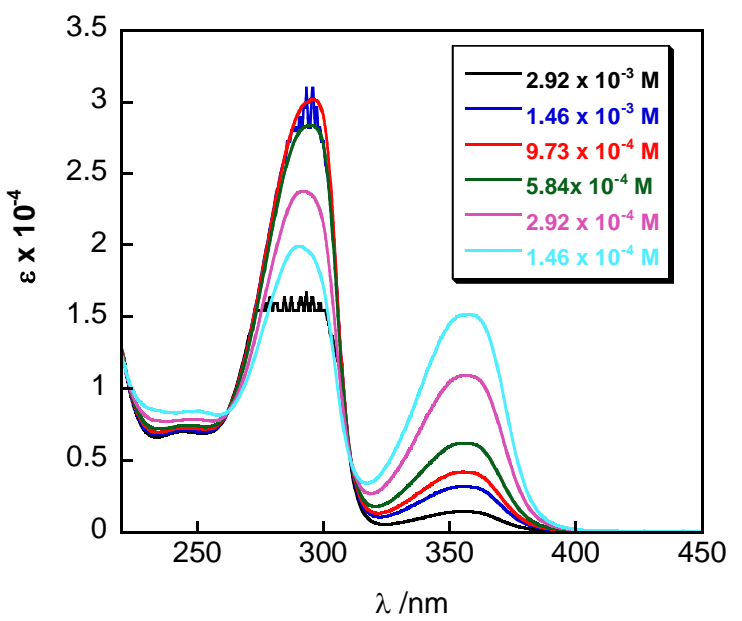

Figure S4. UV spectra of (a) $\mathbf{1} \cdot \mathbf{P} \mathbf{F}_{\mathbf{6}}$ and (b) $\mathbf{1} \cdot \mathbf{T F S I}$ in propylene carbonate (PC) (Optical path length $=1 \mathrm{~mm})$.
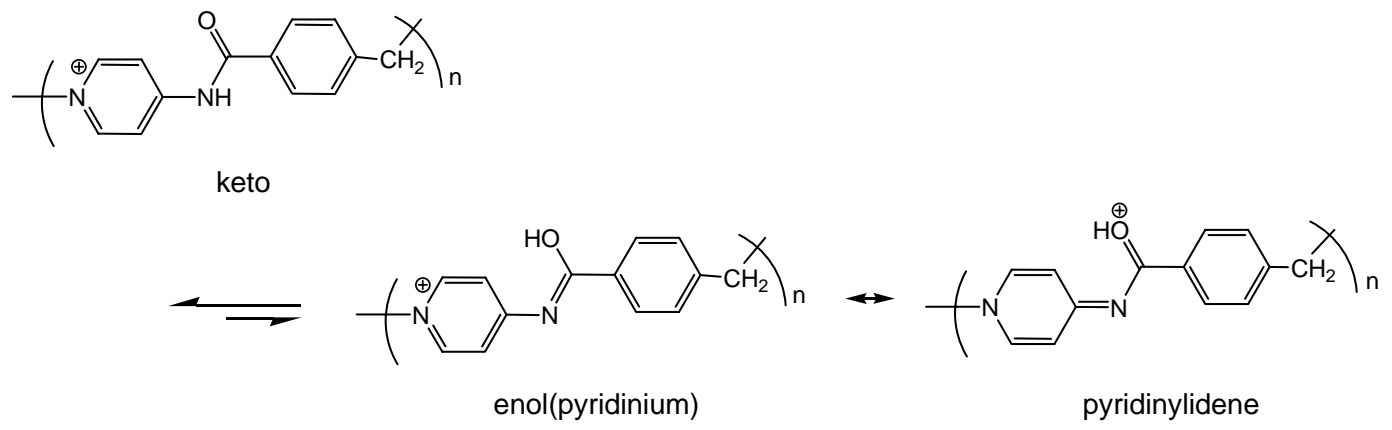

Scheme S1. Plausible equilibrium and tautomerism of the oligomeric electrolyte in solution 


\section{Gelation procedures:}

Gelation was performed as follows: a weight of gelator and solvent in a screw-cap bottle were sonicated using a cleaner bath to form suspension. Then the suspension was heated until the solid dissolved. The solution was cooled at room temperature and then the gelation was checked visually. To estimate the gel-sol phase transition temperature $\left(T_{\mathrm{g}-\mathrm{s}}\right)$, a gel sample in a sealed quartz cell $(d=1 \mathrm{~mm})$ was immersed horizontally in a water bath and gradually heated. $T_{\mathrm{g}-\mathrm{s}}$ was defined as the temperature range at which the gel started melting and eventually disappeared.

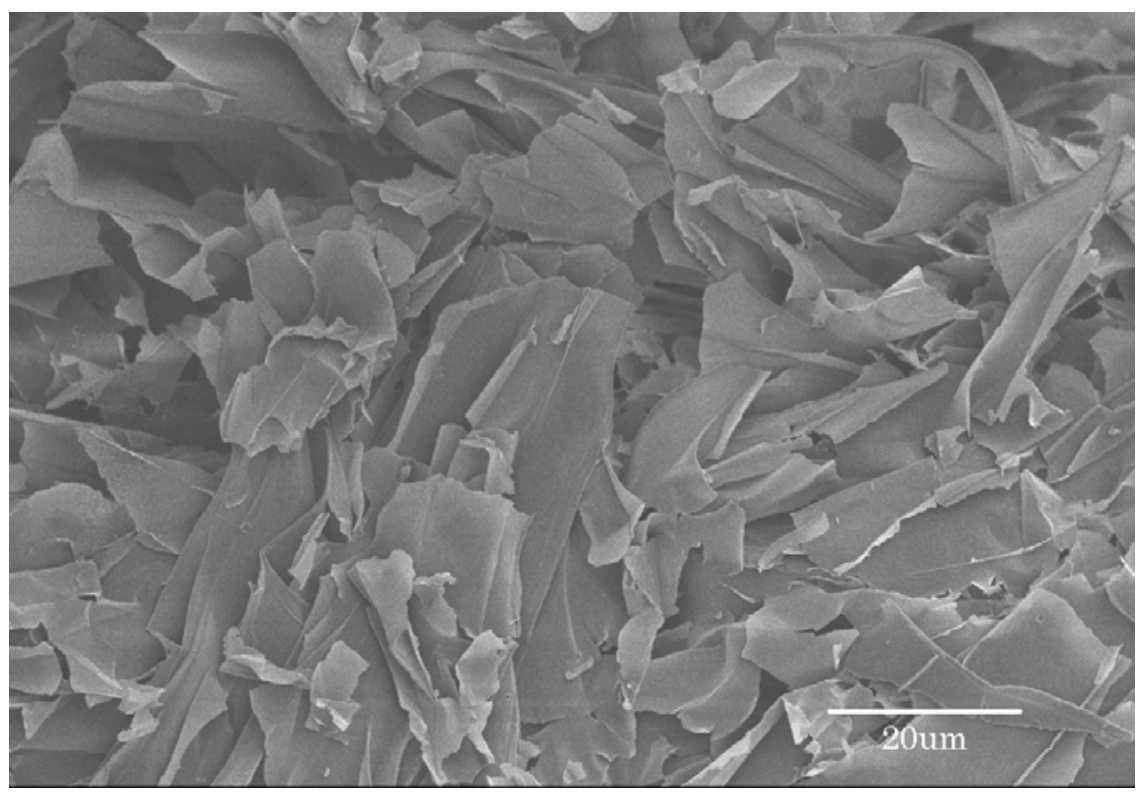

Figure S5. FE-SEM image of xerogel prepared from the hydrogel of $\mathbf{1} \cdot \mathbf{C l}(c=10 \mathrm{~g} / \mathrm{L})$. 


\section{Conductivity Measurements of Ionic Gels:}

The ionic conductivity $(\sigma)$ of the ionic gels was measured by a conductivity meter (Radiometer analytical CDM-230) in a sealed conductivity cell (Radiometer analytical CDC-749) at appropriate temperature controlled by a incubator. Ionic gels were typically prepared with the gelator by heating followed by standing at a room temperature. A conductivity cell was set into the initial hot solution of an ionic liquid containing the gelator before solidification, and then cooling the whole system at room temperature to form an ionic gel.

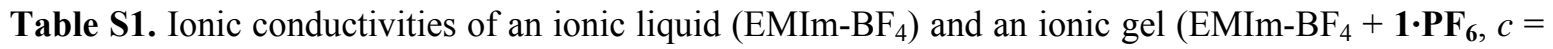
$20 \mathrm{~g} / \mathrm{L})$ at several temperature conditions.

\begin{tabular}{|c|c|c|c|c|}
\hline temperature & $5{ }^{\circ} \mathrm{C}$ & $25{ }^{\circ} \mathrm{C}$ & $35{ }^{\circ} \mathrm{C}$ & $45{ }^{\circ} \mathrm{C}$ \\
\hline $\begin{array}{c}\text { EMIm-BF } \\
(\mathrm{mS} / \mathrm{cm})\end{array}$ & 6.37 & 14.4 & 19.7 & 25.9 \\
\hline $\begin{array}{c}\mathrm{EMIm}-\mathrm{BF}_{4} \\
+\mathbf{1} \cdot \mathbf{P F} \\
(\mathrm{mS} / \mathrm{cm})\end{array}$ & 6.24 & 14.1 & 19.0 & 25.1 \\
\hline
\end{tabular}

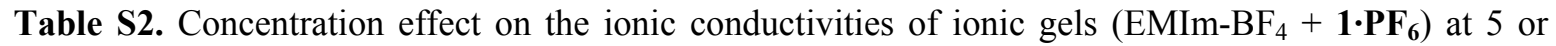
$25^{\circ} \mathrm{C}$.

\begin{tabular}{|c|c|c|c|c|}
\hline concentration & $0 \mathrm{~g} / \mathrm{L}$ & $20 \mathrm{~g} / \mathrm{L}$ & $30 \mathrm{~g} / \mathrm{L}$ & $40 \mathrm{~g} / \mathrm{L}$ \\
\hline $5{ }^{\circ} \mathrm{C}$ & 6.37 & 6.24 & 6.01 & 5.71 \\
\hline $25^{\circ} \mathrm{C}$ & 14.4 & 14.1 & 13.7 & 13.2 \\
\hline
\end{tabular}




\section{$20 \mathrm{~g} / \mathrm{L} 30 \mathrm{~g} / \mathrm{L} 40 \mathrm{~g} / \mathrm{L}$}

Figure S6. Ionic gels of EMIm-BF ${ }_{4}$ with the gelator $\mathbf{1} \cdot \mathbf{P F}_{\mathbf{6}}$ at the concentration of 20,30 and $40 \mathrm{~g} / \mathrm{L}$, respectively.

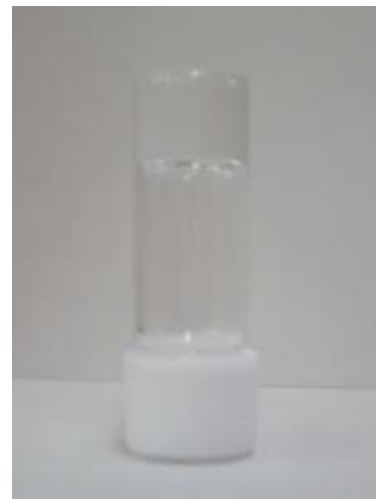

Figure S7. An organogel of $\mathrm{MeOH}$ with 1·TFSI at the concentration of $50 \mathrm{~g} / \mathrm{L}$.

\section{Rheology Analysis:}

Rheological measurements of hydrogels were performed on an ARES-RFS controlled strain rheometer of TA Instruments, equipped with cone-plate geometry $\left(25 \mathrm{~mm}, 4^{\circ}\right.$ angle). All gelatinized samples were prepared at appropriated concentrations using deionized water and stood at least one day at room temperature before measurements. All rheological measurements were carried out at $25{ }^{\circ} \mathrm{C}$ controlled with a Peltier thermo-module unit. An oscillatory strain sweep measurements were performed with the strain amplitude $\gamma=0.1-300 \%$ at the fix frequency $(\omega=1 \mathrm{~Hz})$ to record $G^{\prime}$ and $G$ ”, the linear 
viscoelastic storage and loss module, respectively. When gel samples were mounted on the plate, they were allowed to stand for at least $5 \mathrm{~min}$ to facilitate the recovery of the structure. The continuous recovery measurements were consisted of several steps: (1) Standing the gel sample for 5 minutes after mounting; (2) Linear small-amplitude oscillations (at $\gamma=0.1 \%$ and $\omega=1 \mathrm{~Hz}$ ) for 5 minutes to monitor initial value of $G^{\prime}$ and $G$ ”; (3) Nonlinear, large-amplitude oscillations $(\gamma=100 \%)$ at the same frequency for 10 minutes to breakdown the gel structure; (4) Linear small-amplitude oscillations $(\gamma=0.1 \%)$ for 10 minutes at the same frequency to monitor recovery of mechanical strength of gels; (5) Additional two cycles of the breakdown and recovering processes described in (3) and (4). The measurements were carried out with the solvent-trap to prevent drying a gel sample during the long-time measurement.

\section{Solubilization of SWNT into water:}

Aqueous solution of $\mathbf{1} \cdot \mathbf{C l}$ in a screw-cap bottle was prepared as already described. Then SWNT was added to a solution and sonicated for 1 hour using an ultrasonic cleaner bath $(130 \mathrm{~W}, 35 \mathrm{kHz})$ to form a black solution. In cases of the concentrated condition of $\mathbf{1} \cdot \mathbf{C l}(c>20 \mathrm{~g} / \mathrm{L})$, black colored gel was directly formed by standing the solution at room temperature for 2 hours after the sonication.

\section{Complete reference 13}

13) O'Connell, M. J.; Bachilo, S. M.; Huffman, C. B.; Moore, V. C.; Strano, M. S.; Haroz, E. H.; Rialon, K. L.; Boul, P. J.; Noon, W. H.; Kittrell, C.; Ma, J. P.; Hauge, R. H.; Weisman, R. B.; Smalley, R. E. Science 2002, 297, 593-596. 